\title{
Thinking Mesolithic
}

Stefan Karol Kozłowski

Oxford: Oxbow Books, 2009, 545 pp. (hardback), \$120.00.

ISBN-13: 9781842173350.

\section{Reviewed by PAMELA R. WILLOUGHBY}

Department of Anthropology, University of Alberta, Edmonton, Alberta T6G 2H4, CANADA; Pam.Willoughby@ualberta.ca

$\mathrm{T}$ his volume is composed of Stefan Kozłowski's papers about the Mesolithic, written over the course of almost four decades, from around 1971 until around 2006. They show his evolving ideas about Mesolithic technology and economic systems and from local Polish sites to the continent of Europe as a whole. The papers are mainly in English, but a few are in French, and at least one each in Italian and German. Most of these papers have been revised for this book, and in fact, for some, only a short selection is offered. All have commentaries and updates, prepared in 2006.

I conducted my M.A. research on the European Mesolithic and how it was constructed (Willoughby 1976). One of the first comprehensive sources I obtained was Kozłowski's (1973) edited volume on The Mesolithic in Europe; this was the proceedings of the first international Mesolithic conference, held in Warsaw in 1973. From this book, and from many other sources, it became clear that what defined the Mesolithic was more about absence than presence. It was not Paleolithic, nor Neolithic. These periods were defined by John Lubbock in the 1860s as the ages of flaked and ground stone respectively. One belonged to the Pleistocene, the epoch of the great ice ages, the other was Holocene or postglacial. The Neolithic, of course, went on to be recognized as the material culture of the first farmers and pastoralists in Europe. The recognition of a postglacial occupation of Europe by hunter-gatherers was not accepted until the discovery in the 1890s of the cave site of Mas d'Azil in the Pyrenees of southern France. In the 20th century, however, the Mesolithic remained of little interest to prehistorians. Many of us still think of Pierre Laurent's (1965) cartoons of the hapless Mesolithic hunter-gatherers, just waiting around for another Ice Age; when glacials return, they could go back to painting naturalistic images of animals, rather than the red dots and lines on pebbles of the Azilian, the hunter-gatherers of Mas d'Azil. They might even be able to return to hunting big game, rather than relying on snails, fish, shellfish, and frogs.

I chose to review this book in order to increase my knowledge about the Mesolithic and how ideas about this period have evolved. Kozłowski does not disappoint. While some of his articles were published quite a while ago, he updates them with illuminating commentaries and a refreshing critical assessment of his own ideas. He points out when key changes happened, and how concepts of the Mesolithic have changed over his academic career. As a result, it is a most intriguing book, which has something to offer any archaeologist and paleoanthropologist, whether they follow a processual or post-processual approach.

The first chapter deals with basic definitions, artifact typology, assemblage ordering, and space-time systematics. The classification of artifact types comes from his Atlas of the Mesolithic of Europe. The continent is divided into geographic and/or cultural regions, as marked by the presence of key lithic tool types. Then each macro-region is discussed in detail. At the end of the book, Kozłowski offers a historical synthesis and conclusions about key events in Mesolithic time.

For him, it started with his organizing the first International Symposium on the Mesolithic in Europe. This was held in Warsaw in 1973 (Kozłowski 1973). He had already studied the Polish Mesolithic, and thought that he could go on to address cultural developments in the whole continent. In retrospect, he sees himself as "young and ambitious, not to say naïve" (p. 1). At that time, and even now, there were two basic definitions for the Mesolithic. The first is the common concept of it being the time period between the Paleolithic and Neolithic, where material culture was dominated by stone microliths and other geometric tools. The other, he says, was a more restricted definition. It saw the Mesolithic as the product of hunters-fishers-gatherers living in the European lowland in the early Holocene. This was more a stage of cultural and economic development, of people adapted to new forested conditions of the postglacial. But he always stressed that Mesolithic economies were lifeways inherited from late glacial ancestors, not invented in the Holocene. He states that "the Mesolithic is a stage of "WAITING" or "QUARANTINE," which was realized in an environment where primitive agriculture could not develop" (p. 4). This is an unusual idea, as it almost implies that the Neolithic is inevitable, and that postglacial foragers are just waiting for it to happen. The rest of this chapter reproduces his own presentations to several international conferences, as a way to illustrate his own changing views about the Mesolithic.

Chapter 2 is titled "What and how?" It focuses on the material culture of the Mesolithic. Much of what is discussed deals with lithic analysis, but organic tools, dwellings, and camp sites are also described. Kozłowski states that researchers have had to deal with continuing stereotypes about Mesolithic technology. These stereotypes involve the belief that the Mesolithic was essentially the same all over Europe, and that because the stone tools were microlithic, they had to have been used solely for hunting 
small animals. Both of these have been proven to be wrong. Chapter 3 (or "Where?") deals with European geography, and how it changed over time with the retreat of ice sheets. It reviews the landscape, as well as available resources for hunter-gatherers. Chapter 4 (or "There") focuses on mapping the distribution of Mesolithic sites and diagnostic tools. This leads Kozłowski to define the six regional provinces which will be the focus of the second half of this book.

Chapter 5 (or "When?") focuses on the temporal sequence for the Mesolithic. Kozłowski (p. 188) concludes that the chronological system "is fairly well developed and rather uncontroversial." He uses the appearance and spread of various key elements in order to develop models of cultural evolution. Whether these represent acculturation or migration is not yet clear. His chronological sequence starts around the 11th millennium cal BC with the retreat of ice sheets in Europe. Hunter-gatherers (and their distinctive artifacts) spread into the new lands, bringing their Upper Palaeolithic adaptations with them. But they are soon forced to change. Kozłowski talks about cultural trends over time. One is Azilianization (after the original type site of Mas d'Azil), which is marked by a steady decrease in size of stone tools. Another is called Sauveterrization (after the site of Sauveterre in France). This is marked by the appearance and spread of slender triangular tools with short bases (or trapezes). Another is Castelnovization (from the Castelnovo region of the Mediterranean), which is marked by the emergence of larger blade and bladelet tools, long distance transport of raw materials, and new types of geometrics (trapezes, rhomboids). It first appears in the south, at sites such as Franchthi Cave in Greece, and spreads north to Kongemose, Denmark, in only about 500 years, from 7000 to $6500 \mathrm{cal} \mathrm{BC}$. It correlates with the northward expansion of forests during the Atlantic palaeoenvironmental period, and immediately predates the appearance in Europe of Neolithic farmers. Following all of these is a period of the appearance and spread of pottery ("ceramicization"), then the Neolithic.

Part II, making up Chapters 6 to 11, the bulk of the book, divides Mesolithic Europe into six areas-the South, the Southeast, the West, and the Center (grouped into a single chapter), the East, and the North. Each is discussed in turn, with a focus on major sites and their contents. These are examined in terms of what Kozłowski calls their environmental, cultural, and historical dimensions. Chapter 11 deals with the Castelnovian, the late Mesolithic and /or preNeolithic period. Chapter 12 discusses the production of bone, antler, and amber items, including ornaments, figurines, and other organic tools. Kozłowski points out that these non-lithic artifacts are only known from certain areas.

The final chapter (Chapter 13) offers some conclusions. Like many others, Kozłowski stresses the limits of the archaeological data. Only certain sites are preserved, and organic items are seldom common. Archaeologists have difficulties in interpretation, and researchers still have their own traditions of research. He comes back to classification and how one identifies geographic territories, archaeological cultures, techno-complexes, and/or ethnic groups. But he does believe that the empty land of northern and midlatitude Europe became the home of dynamic cultures, no less complex than those of earlier or later prehistory.

In general, this is an excellent book that shows the evolution of one scholar's views over time, as well as how our ideas about the Mesolithic have changed. This is truly a magnum opus, and quite an achievement, for which Kozłowski should be thanked. The numerous line drawings and maps bring us into the Mesolithic world, and remind us that postglacial hunter-gatherers in Europe had a new and varied lifestyle. As their environment changed, as the world warmed, they were able to survive and flourish. As we know from the genetics of living Europeans, many Mesolithic people eventually adopted the new agricultural way of life, and blended it in with their reliance on natural resources. In no way were they replaced by Neolithic newcomers.

\section{REFERENCES}

Kozłowski, S.K. 1973. The Mesolithic in Europe. International Archaeological Symposium on the Mesolithic in Europe, Warsaw: Warsaw University Press.

Laurent, P. 1965. Heureuse Préhistoire. Périgueux: Pierre Fanlac.

Willoughby, P.R. 1976. An Analysis of Early Postglacial European Prehistory. Edmonton: Master of Arts thesis, University of Alberta. 